Eurasian Journal of Business and Economics 2019, 12(24), 65-86.

\title{
Estimating Factors Affecting Technical Efficiency in Indian Manufacturing Sector
}

\author{
Ajay Kumar SINGH*, Shah Nawaz ASHRAF ${ }^{* *}$, Ashish ARYA*** \\ Received: June 14, 2018. \\ Revised: August 4, 2019. \\ Accepted: November 12, 2019.
}

\begin{abstract}
Existing studies could not estimate the technical efficiency (TE) of firms and it's affecting factors in the Indian manufacturing sector. So, the present study examines the TE of firms using a stochastic frontier production function approach. Thereupon, it examines the impact of S\&T and IPRs related factors on estimated TE of firms using a linear regression model. Estimated values of TE of firms show that most firms have a TE of 94\%; thus, firms are efficient in producing surplus production in the manufacturing sector. It is acclaimed that firms can improve production scale using more technological upgradation and advancement. Furthermore, empirical results indicate that process innovations of firms, quality certification of firm, firm acquired process/product patents, in-house R\&D expertise of firms, public-technology support institutions of firms, proficiency to improve processes of firms, new or improved products of firms, waste management capabilities of firms, and skilled workforce of firms are appeared effective activities to increase the TE of firms. It is proposed that there is a requirement to increase $R \& D$ expenditure, a collaboration of industries with research academia, incentive to researchers and scientists to do extensive research in emerging sectors of technologies and appropriate financial support to firms to boost the growth of Indian manufacturing sector.
\end{abstract}

Key Words: Technical efficiency, SFPFA, S\&T and IPRs related factors, Micro, Small and Medium Enterprises, Manufacturing sector, India.

JEL Classification: L60, L62, L64, L65, L67, 014, 031, 033, 034.

UDC: $330.4(338.27)$

DOI: https://doi.org/10.17015/ejbe.2019.024.04

\footnotetext{
* Assistant Professor of Economics, Department of Humanities and Social Sciences, DIT University, Dehradun Uttarakhand, India. Email: a.k.seeku@gmail.com; kumar.ajay_3@yahoo.com.

** Fellow Program Management (PhD Student), EDI of India, Ahmedabad. Email: shah.ashraf2013@gmail.com.

*** Project In-charge, Centre of Technology and Entrepreneurship Development (CTED), Jagdishpur, Amethi (UP)-India. Email: ashisharya95@gmail.com.
}

Copyright (C), 2019 Ala-Too International University. 


\section{Introduction}

At present, the world has around 7.2 billion population, and it is expected to be increased by 9.6 billion by 2050 . Thus, it would be a serious challenge for national and global policymakers, development thinkers, international development organizations and stakeholders to create more jobs for the present and growing population worldwide. The agriculture sector provides jobs to around $40 \%$ population of the world (Kumar, Sharma \& Joshi, 2016). While, arable land and water availability for irrigation have declined due to overwhelming urbanization and industrialization at world-wide (Kumar, Sharma \& Ambrammal, 2015; Kumar, Sharma \& Joshi, 2016; Singh, Ahmad, \& Sharma, 2017; Singh \& Sharma, 2018a,b; Singh \& Jyoti, 2019). Thus, the agricultural sector would be unable to create more jobs for a growing population in the near future. As the service sector creates jobs for educated and skilled workers, thus it have limited jobs. Therefore, the manufacturing sector might be helpful to create additional jobs for present and future generations through the growth of Micro, Small and Medium Enterprises (MSMEs).

It is apparent that Micro, Small, and Medium Enterprises (MSMEs) under the manufacturing sector have an effective contribution to increase social and economic development in India (Ali \& Husain, 2014; Aruna, 2015; Srinivasan, Bajaj \& Bhanot, 2016). Around 106 million population of India are working in MSMEs (Kumar \& Ayedee, 2018). MSMEs are also helpful in increasing industrial output and exports of goods and services at the global level. India is the home of $2^{\text {nd }}$ largest populated country after China and it is going to be the $1^{\text {st }}$ populated country of the world by 2024 (Arcanjo, 2019). Moreover, India has achieved impressive economic growth at a sustainable basis in the current decade (Green, 2014). India has achieved around $7.2 \%$ annual growth in the gross domestic product (GDP) in 2016 and growing faster than other emerging economies like China, South Korea, South Africa and Russia (Hoda \& Rai, 2014). Despite that, India could not create appropriate jobs for skilled and unskilled workers due to the insignificant growth of its manufacturing sectors (Green, 2014).

In India, GDP growth is increased due to the higher growth of the service sector. Also, the service sector could create jobs for a skilled workforce in India. On the other hand, the livelihood security of a large portion of the Indian population depends upon the agricultural sector (Green, 2014; Kumar, Sharma \& Ambrammal, 2014; Kumar, Sharma \& Joshi, 2016; Singh \& Issac, 2018). So, it is important for the Indian policymakers to give more priority to increase the growth of the manufacturing sector. Thereafter, it may be effective to create surplus jobs for the youth population in India (Kapoor, 2016). In India, the growth of the manufacturing sector is stuck, and it contributes around $17 \%$ share in India's GDP, which is significantly lower than other emerging economies like China, South Korea Indonesia and Malaysia (WDI, World Bank, 2016). In 2014, the manufacturing sector could contribute around a $17.05 \%$ share in the GDP of India (WDI, World Bank, 2016). India's manufacturing 
sector could not get dynamic progress due to its lowest participation in the international production network (Hoda \& Rai, 2014; Bhat, 2014).

Furthermore, it is also witnessed that appropriate science \& technology (S\&T) and innovation, and intellectual property rights (IPRs) related policies have created several options for additional jobs in most economies like China, South Korea, Thailand and USA (Wei \& Balasubramanyam, 2015; Singh, Acharya \& Chavda, 2017). Consequently, S\&T and IPRs related activities have prepared a conducive platform for social and economic development in these economies (Yueh, 2007; Janjua \& Samad, 2007; Sattar \& Mahmood, 2011; Odilpova, 2016; Singh, Acharya \& Chavda, 2017; Singh, Ashraf \& Acharya, 2017). It also provides further possibilities for technological development and reduction of imitations in technologies within an economy and across countries (Falvey \& Foster, 2006; Yueh, 2007; Shugurov, 2015).

It is projected that the manufacturing sector has created huge jobs for skilled, semiskilled and unskilled workers in China, Thailand, and South Korea. Subsequently, the economic capacity of the population to sustain their lives have improved in these economies. So, the manufacturing sector has a greater share in their gross domestic products (GDP) in these countries. Due to the aforementioned reason, the manufacturing sector is appeared as a prime source of stronger and sustainable economic growth in most economies (Patnaik \& Satyaprakash, 2015). Also, it has proved that competitive manufacturing is the lifeblood that builds a foundation for long-term social prosperity and economic development of a nation (Bhat, 2014; Chaudhuri, 2016).

In India, numerous of studies have estimated the impact of different factors such as social media, specific leadership skills, communication skills, human skills, technical skills, and other socio-economic characteristics of firms on growth of Micro and Small Enterprise, MSMEs, and firms in various industries in manufacturing sector (Ghani, Kerr \& O'Connell, 2013; Chatterjee \& Das, 2016; Srinivasan, Bajaj \& Bhanot, 2016; Lakshmi, Mahboob \& Choudhry, 2017; Kumarasamy \& Srinivasan, 2017; Kumar \& Ayedee, 2018). However, limited studies could examine the impact of S\&T and IPRs related indicators on the growth of different firms in the Indian manufacturing sector. Hence, it is expected that S\&T and IPRs related activities would bring better jobs for the youth population in India. For aforesaid perspectives, inadequate studies could investigate the association of science \& technological and IPRs related activities on manufacturing sectors using firm's level data in different industries such as automobile and auto components, construction (equipment, materials \& technology), chemicals and petrochemicals, industrial equipment \& machinery (electrical machinery), electronics, pharmaceuticals, and textiles and apparels in India. Also, the limited study examines the technical efficiency (TE) of firms in various industries of India. Due to the existence of the aforesaid research gap, the present study is desired to enquire the answers on a few specific research questions which are specified as: 
- What may be the role of science \& technology (S\&T) and innovation, and intellectual property rights (IPRs) related activities in the growth of the Indian manufacturing sector?

- How and why technical efficiency (TE) of firms are being varied across industries in India manufacturing sector?

- Whether estimated technical efficiency (TE) of firms have an association with science \& technology and intellectual property rights (IPRs) related variables or not?

- What must be policy action to boost the growth of various industries in India manufacturing sector?

Related to the above-mentioned research question, the present study achieved the following research objectives:

- To examines the technical efficiency (TE) of selected 154 firms in 7 different industries in the Indian manufacturing sector using a stochastic frontier production approach.

- To investigate the influence of IPRs and S\&T related variables on estimated TE of selected 154 firms in the Indian manufacturing sector using a linear regression model.

- To provide sector-specific policy recommendations to boost the growth of the manufacturing sector in India.

\section{Theoretical Framework of Stochastic Frontier Production Function Approach}

Stochastic frontier production function approach (SFPFA) and data envelopment analysis (DEA) are the two main techniques which can be used to estimate the technical efficiency (TE) of firms/industries and other sectors of the economy (Aigner, Lovell \& Schmidt, 1977; Meeusen \& Van den Broeck, 1977; Chavas \& Aliber, 1993; Kumbhakar \& Lovell, 2003; Rajesh, 2007; Faruq \& Yi, 2010; Akpan et al., 2012; Pattnayak \& Chadha, 2013; Kumar \& Arora, 2012; Hamjah, 2014; Zhou, 2014; Mahajan, Nauriyal \& Singh, 2014; Debnath \& Sabastian, 2014; Bhatia \& Mahendru, 2015; Munisamy, Fon \& Khin, 2015; Sahu, 2015; Ng'ombe \& Kalinda, 2015; Narwal \& Pathneja, 2015; Ikram, Su \& Sadiq, 2016); Okoye et al., 2016; Kea, Li \& Pich, 2016; Vu, 2016; Fahmy-Abdullah et al., 2017; Gebresilassie, \& Nyatanga, 2017; Singh, Narayanan \& Sharma, 2018; Singh, Narayanan \& Sharma, 2019). Efficiency is defined as the best allocation of resources to achieve the highest level of output (Bhatia \& Mahendru, 2015). Earlier studies have emphasized that the SFPFA model is more effective and rational to estimate the TE of all sectors as compared to other methods (Fahmy-Abdullah et al., 2017; Singh, Narayanan \& Sharma, 2018).

Moreover, it has a greater benefit to assess the impact of explanatory variables on a firm's output. SFPFA model produces regression coefficients of explanatory variables that have a significant association with output, including TE. It can be used in the case of parametric and non-parametric conditions (Ng'ombe \& Kalinda, 2015; Okoye et al., 2016). Existing researchers have used SFPFA model to investigate the impact of various factors on output and to examine the TE of individual firm (Akpan et al., 
2012; Pattnayak \& Chadha, 2013; Zhou, 2014; Sahu, 2015; Ikram, Su \& Sadiq, 2016); Vu, 2016; Fahmy-Abdullah et al., 2017). SFPFA model has also predicted the frontier level of inputs in the production activities of firms (Fahmy-Abdullah et al., 2017). Technical efficiency (TE) is a measurement of a firm or industry which is capable to produce maximum output using a minimum quantity of inputs (Kumbhakar \& Lovell, 2003). TE is useful to reduce the waste of inputs to produce goods in manufacturing firms (Ikram, Su \& Sadiq, 2016).

Technical efficiency (TE) measures the ability of producers in manufacturing firms to produce the maximum amounts of output using available inputs and technologies (Kea, Li \& Pich, 2016). TE is also useful to estimate allocative, production, and economic efficiency of manufacturing firms (Rajesh, 2007; Bhatia \& Mahendru, 2015; Kea, Li \& Pich, 2016; Fahmy-Abdullah et al., 2017; Singh, Narayanan \& Sharma, 2018). Economic efficiency is achieved if the highest possible level of satisfaction is obtained from given resources in a manufacturing firm (Ikram, Su \& Sadiq, 2016). Production efficiency is concerned with the relative performance of the process that is used to transformation of input(s) into output(s) in manufacturing firms (Kea, Li \& Pich, 2016). Allocative efficiency measures the ability of a firm/producer to produce a high quantity of output using the minimum cost of inputs in a manufacturing firm (Rajesh, 2007; Hamjah, 2014). Thus, the measurement of TE and its elements in firms or industries is a vital concept in production theories (Fahmy-Abdullah et al., 2017).

In a production unit, efficiency measures the level of process which produces the maximum quantity of output using the lowest quantity of inputs (Kea, Li \& Pich, 2016; Singh, Narayanan \& Sharma, 2019). In general, efficiency is associated with inputs (e.g., labor, capital, land, finance, managerial skills, technologies, etc.) which use to produce goods and services in manufacturing firms. The value of TE lies between 0 - 1 (Bhatia \& Mahendru, 2015; Kea, Li \& Pich, 2016; Sen \& Das, 2016; Ikram, Su \& Sadiq, 2016); Fahmy-Abdullah et al., 2017). In India, limited studies estimate the TE of firms in manufacturing sectors using SFPFA. SFPFA produces regression coefficients of explanatory variables that have a significant association with output including TE (Akpan et al., 2012; Pattnayak \& Chadha, 2013; Zhou, 2014; Kea, Li \& Pich, 2016; Okoye et al., 2016). Also, limited studies used primary information at the firm level to estimate the TE of firms in India. SFPFA includes parameters of production function and inefficiency function simultaneously in a proposed empirical model (Akpan et al., 2012; Zhou, 2014). Hence, this study is used SFPFA to examine the TE of selected firms in the Indian manufacturing sector.

\section{Review of Existing Literature}

In India, numerous studies have estimated the technical efficiency (TE) of firms in the manufacturing sector using secondary data and firm-level information. The brief explanation of earlier studies and their major findings are given as: Rajesh (2007) has measured the TE of small and micro enterprises in Kerala (India) using a translog stochastic frontier production function approach. It found that TE of enterprises is 
significantly associated with the size of enterprise, ownership of firm, geographical local and seasonal operation. Sahu and Narayanan (2011) have estimated the determinants of energy intensity of manufacturing firms in India using the non-linear regression model. It perceived that firm size has a non-linear association with the energy intensity of firms. Kumar and Arora (2012) have examined the inter-temporal and inter-state variations in TE of sugar industries in India using the envelopment analysis approach.

Pattnayak and Chadha (2013) have estimated the TE of selected 76 pharmaceutical firms using firm-level panel data in India during 1991-2003. It observed that the overall TE of firms have increased during 1991-2003. However, patenting firms have more TE as compared to non-patenting firms. Mahajan, Nauriyal, and Singh (2014) have assessed the TE of pharmaceutical firms in India using the Data Envelopment Analysis (DEA) technique. It observes that productivity and efficiency of firms improve as an increase in inputs cost on advertisement and marketing, and applications of skill labors in the manufacturing sector. Debnath and Sabastian (2014) have perceived the TE of steel manufacturing industries in India using the DEA technique. It includes the output of firms and gross fixed assets, current assets, total energy and total employee as inputs to estimate the TE of firms.

Sahu and Narayanan (2015) have examined the TE of Indian manufacturing firms. Also, it assesses the impact of environmental certification on TE of firms. It detects that firm age, firm size, debt capital, MNE affiliation, and ISO certification have a significant impact on various sizes of firms. Sahu (2015) has estimated the TE of domestic and foreign firms of various industries in the manufacturing sector in India. It observes that TE of foreign firms in five industries (i.e., chemical, machinery, electronics industry, and transport) are appeared higher than Indian firms. Narwal and Pathneja (2015) have assessed the productivity and profitability of the banking system in India using the DEA method. It witnessed that private sector banks have more productivity than public sector banks. Bhatia and Mahendru (2015) have estimated the TE of public sector banks in India using the DEA approach.

Sen and Das (2016) have examined the TE of various enterprises in the India manufacturing sector using the DEA approach. It shows that estimated TE varies across firms in India. Kumar and Sharma (2016) have assessed the influence of patenting on an estimated TE of Indian high and medium technologies firms. It has appeared that research \& development (R\&D) has a little impact on TE of high and medium technology firms in India. Tyagi and Nauryal (2016) have examined the determinants of profitability of the drug and pharmaceutical industry in India during pre and post TRPS periods. It found that the profitability of industries is positively associated with export intensity, A\&M intensity, and post-product patent regime. Bawa and Chattha (2016) have assessed the role of intermediary channels like individual agents, corporate agents, brokers and direct selling in life insurance in India. It found that individual agent plays a crucial role to boost the business. Mishra (2019) has assessed the influence of mergers and acquisitions on the financial 
performance of firms in India using firm level data. It recommended that financial performance of firms are significantly associated with competition policies and law, international trade, investment, and technology development.

Furthermore, numerous studies have estimated the TE of various firms in developed and developing economies using data envelopment analysis (DEA) approach and stochastic frontier production function approach (SFPFA). Faruq and Yi (2010) have estimated the TE of manufacturing firms in Ghana using the DEA technique. It observed that the firm's size, age of the firm, foreign ownership and labours are the critical factors affecting the TE of firms in Ghana. Alvarez and Crespi (2011) have evaluated the firm's efficiency affecting factors in the Chilean manufacturing sector. It observed that the efficiency of firms is positively associated with the experience of workers, modernization of physical capital and innovation in products. Akpan et al. (2012) have estimated the TE affecting factors in sugar industries in Nigeria using SFPFA. It considers the firm's output as a dependent variable which is regressed with the firm's level variables. Accordingly, it used estimated TE as a dependent variable that is regressed with the firm's level variables to measure the TE affecting variables in sugar industries in Nigeria.

Zhou (2014) has assessed the impact of foreign direct investment (FDI) on the firm's TE using SFPFA in five African economies. It found that firm size and export behavior are useful to increase the firm's efficiency. Munisamy, Fon and Khin (2015) have examined the TE of the family manufacturing firms in Malaysia using DEA. Thereafter, it used the Tobit regression model to assess the crucial determinants of TE. Vu (2016) has measured the TE of FDI firms in the manufacturing sector in Vietnam using SFPFA. It found that net revenue per labor, the firm's age are positively associated with TE of firms. Lehtimaki and Lehtimaki (2016) have examined the association of knowledge of capital with the economic performance of firms in Finland. In this study, capital knowledge is measured in terms of R\&D, market structure, flexibility of internal structures, uniform routines, and effectiveness of customer relationships, customer loyalty, and customer satisfaction.

Fahmy-Abdullah et al. (2017) have estimated the TE of selected 130 transport manufacturing firms in Malaysia using SFPFA. It perceived that employes' wage rate and cost of information are significantly associated with TE of transport manufacturing firms in Malaysia. Dogan et al. (2019) have assessed the determinants of performance of companies operating in manufacturing industries in Turkey. It perceived that the performance of manufacturing firms is significantly associated with innovation, $R \& D$, and exports.

\section{Description of Study Area and Source of Data}

\subsection{Brief Outline of Study Area}

The present study includes the firms-level data of various industries from nine states of India which are given as Maharashtra, Gujarat, Tamil Nadu, Karnataka, Telangana, 
Delhi, Uttar Pradesh, Punjab and Haryana. These states are taken from various regions of India i.e. West Region (Maharashtra and Gujarat), South Region (Tamil Nadu, Karnataka, and Telangana), and North Region (Delhi, Uttar Pradesh, Punjab and Haryana). These states contribute around $70 \%$ output of the manufacturing sector of India (Centre for Monitoring Indian Economy (CMIE), 2016).

\subsection{Methods for Data Collection}

The present study is based on primary data, which is collected from the randomly selected 154 firms in 7 different industries: (i) Automobile and auto components, (ii) Construction (equipment, materials \& technology), (iii) Chemicals and petrochemicals, (iv) Industrial equipment \& machinery (electrical machinery), (v) Electronics, (vi) Pharmaceuticals, and (vii) Textiles and apparels. In this study, 22 firms from each industry are randomly selected from nine states of India. For this study, 154 firms included small, medium and large firms (Refer to Figure 1). These firms are taken from Maharashtra, Gujarat, Tamil Nadu, Karnataka, Telangana, Delhi, Uttar Pradesh, Punjab and Haryana states of India (Refer to Figure 2). This study includes only those firms which are identified by the Ministry of Micro, Small and Medium Enterprises (MSMEs), Government of India (Gol).

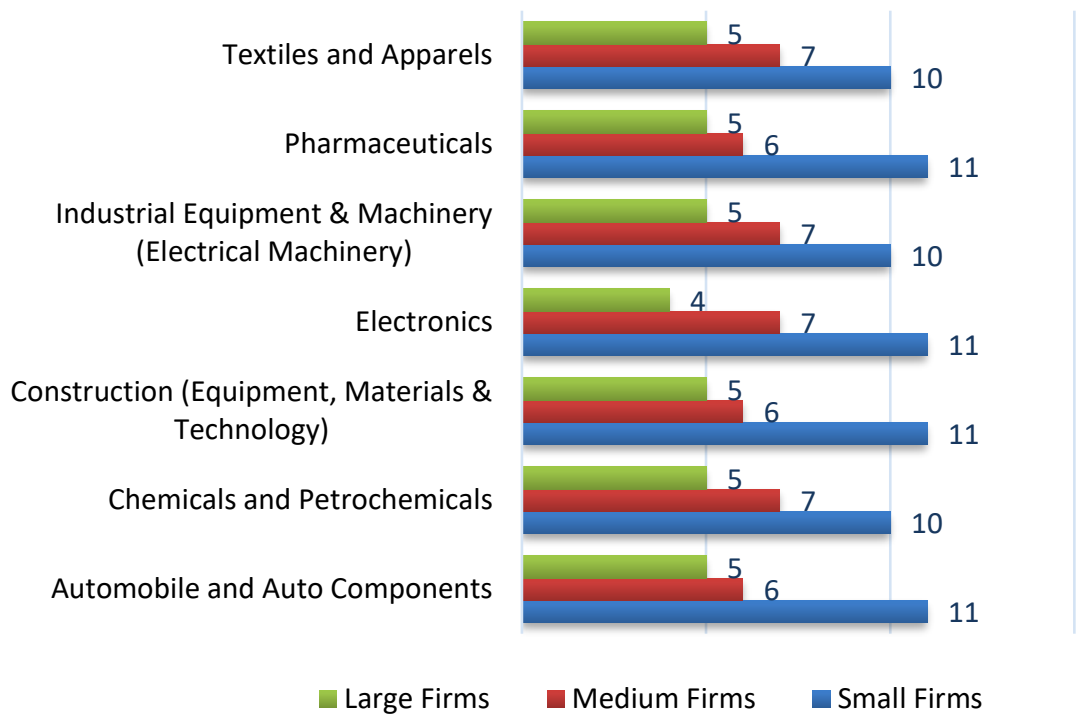

Figure 1: Sector-wise and size-wise distribution of selected firms across India

Source: Based on field survey. 


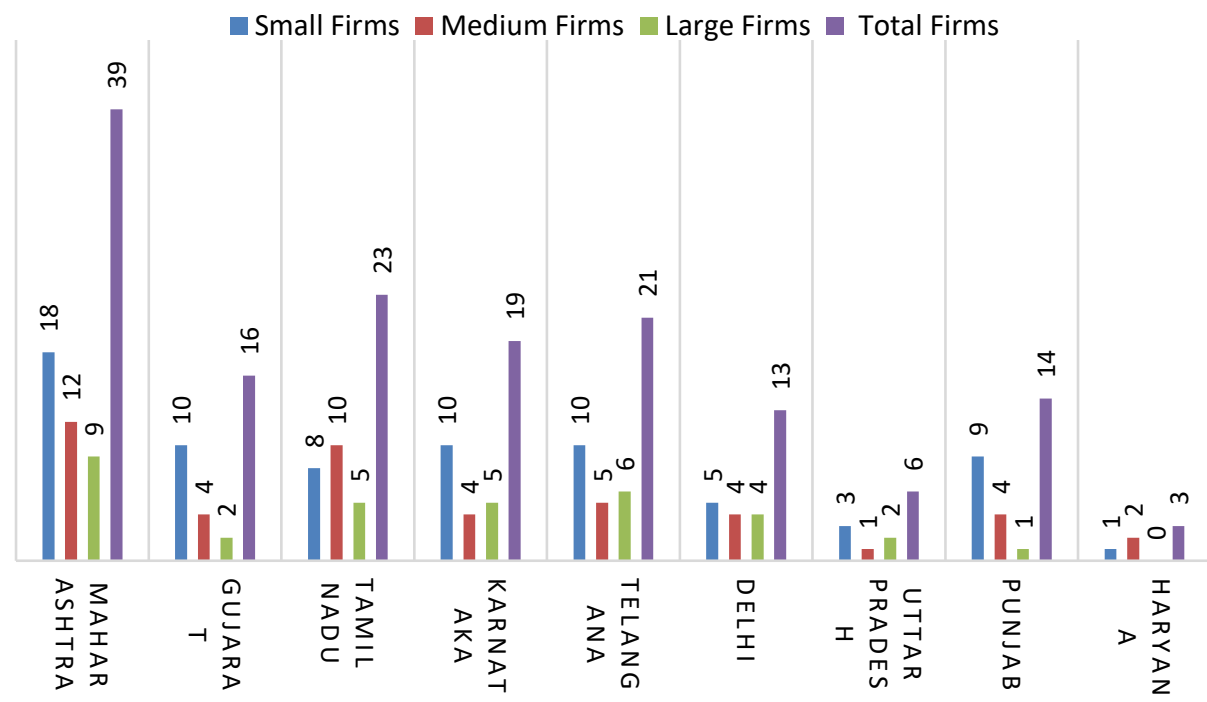

Figure 2: State-wise distribution selected firms across Indian states Source: Based on a field survey.

The structural questionnaires are used to conduct in-depth face to face interviews of randomly selected respondents/representatives/delegates in identified firms. Structural questionnaire includes information on socio-economic characteristics of firms, annual turnover of firms, firm's size, age of the firms, innovation capacity of firms, types of innovation, barriers in innovation, production scale of firms, number of skilled and unskilled workers, R\&D expenditure, firm's annual expenditure on marketing, annual salary and/or wages of firms, number of researchers and scientists, association of firms with public and private research organization, association of firm's with national and international organizations, understanding of firms towards IPRs policy and other policies in MSMEs, etc. The survey of selected firms in India is conducted in March 2016 to May 2016.

\section{Data Analysis and Proposed Empirical Methodology}

\subsection{Mathematical Description of Stochastic Frontier Production Approach (SFPFA)}

SFPFA is developed by Aigner, Lovell and Schmidt (1977); Meeusen and Van den Broeck (1977) in 1977. It includes the two components: non-negative and systematic distribution. The model is specified as (Rajesh, 2007; Pattnayak \& Chadha, 2013; Fahmy-Abdullah et al., 2017):

$Y_{i}=f\left(X_{i}, \beta\right) \exp \left(e_{i}\right)$

$Y_{i}=f\left(X_{i}, \beta\right) \exp \left(v_{i}-u_{i}\right)$ 
Here, $Y_{i}$ is the output of $i^{\text {th }}$ firms; $X$ is the production inputs; $\beta$ is the vector of regression coefficients of explanatory variables (Pattnayak \& Chadha, 2013; Zhou, 2014; Fahmy-Abdullah et al., 2017). $e_{i}$ is the random noise error term that is a combination of $u_{i}$ and $v_{i}$, and $e_{i}\left(=v_{i}-u_{i}\right)$ and it is the identically and normally distributed $\left[N\left(0, \sigma^{2}\right)\right]$. Here, ui may be considered truncated-normal distribution with zero mean $(\mu)$ and constant variance $\left(\sigma^{2}\right)$ (Pattnayak \& Chadha, 2013; Zhou, 2014). In the aforesaid equation, $u_{i}$ is also a one-sided inefficiency; $u_{i}$ and $v_{i}$ are also normally distributed for different firms.

\subsection{Measurement of Technical Efficiency (TE)}

TE measures the ability of a firm to use minimum resources (inputs) to achieve maximum production (output) (Chaudhuri, 2016; Singh, Narayanan \& Sharma, 2019). It infers the ratio of the expected output with the frontier output of a firm (Rajesh, 2007; Akpan et al., 2012). TE of a firm can be assessed using the following formula (Akpan et al., 2012; Pattnayak \& Chadha, 2013; Zhou, 2014; Fahmy-Abdullah et al., 2017):

$T E_{\mathrm{i}}=\exp \left(-u_{i}\right)$

Here, $T E_{i}$ is the technical efficiency of $i^{\text {th }}$ firm, and $u_{i}$ is estimated from equation (2). If the value of technical efficiency of a firm is equal to 1 then it may be considered that firm have a technical efficiency (Rajesh, 2007; Kumar \& Arora, 2012; Akpan et al., 2012; Pattnayak \& Chadha, 2013; Zhou, 2014; Fahmy-Abdullah et al., 2017; Gebresilassie, \& Nyatanga, 2017). While, 1 - TE shows the efficiency gap between actual production and optimal possible production which may be achieved through adjusting the available inputs in production activities of firms (Chavas \& Aliber, 1993; Rajesh, 2007; Bhatia \& Mahendru, 2015).

\subsection{Empirical Model for Technical Efficiency (TE)}

Faruq and Yi (2010) have assessed the determinants of TE of firms in Ghana. It includes the firm-specific characteristics such as age, size, labour-capital mix and foreign status as independent variables, and estimated TE of the firm as a dependent variable. Akpan et al. (2012) have considered estimated TE as a dependent variable to assess the impact of firm-level variables on it of sugar industries in Nigeria. Bhatia and Mahendru (2015) have assessed the determinants of TE of banks in India. Gebresilassie and Nyatanga (2017) have examined the TE of a rural health extension program and TE affecting factors in Ethiopia using the DAE method. Fahmy-Abdullah et al. (2017) have estimated the TE of transport manufacturing firms assess the TE affecting factors in Malaysia. Rajesh (2007) has assessed the determinants of the estimated TE of SMEs in Kerala (India). Kumar and Sharma (2016) have also assessed the impact of R\&D and patenting on TE of high and medium firms.

In the present study, estimated TE of selected firms is used as dependent variable and it regressed with S\&T and intellectual property rights (IPRs) related factors. It also produce the association of estimated TE of firms with S\&T and IPRs related 
indicators in Indian manufacturing sector. For this, linear regression model is used in following empirical form:

$t e_{i}=\beta_{0}+\beta_{1}(\text { pretrf })_{i}+\beta_{2}(n p i f)_{i}+\beta_{3}(n p r i f)_{i}+\beta_{4}(f s g)_{i}+\beta_{5}(f h f c)_{i}+\beta_{6}(f a f f)_{i}+\beta_{7}(b c f)_{i}+$ $\beta_{8}(\text { fhgsp })_{i}+\beta_{9}(\text { fhqc })_{i}+\beta_{10}($ fappp $) i+\beta_{11}(\text { ihrdef })_{i}+\beta_{12}(\text { Iprdif })_{i}+\beta_{13}(\text { Iprdtsf })_{i}+\beta_{14}$ $(\text { pipf })_{i}+\beta_{15}($ pnpf $) i+\beta_{16}(\text { apppf })_{i}+\beta_{17}(w m c f)_{i}+\beta_{18}(f f p s s w)_{i}+\varepsilon_{i}$

Here, te $i$ is estimated TE of $i^{\text {th }}$ firms; $\beta_{0}$ is the constant coefficient; $\beta_{1} \ldots \beta_{18}$ are the regression coefficients of corresponding explanatory variables; and $\varepsilon_{i}$ is simple random-error term in equation (4). While, detail description of explanatory variables are given in Table 1.

\section{Table 1: Brief descriptions of dependent and explanatory variables}

\begin{tabular}{lll}
\hline \multicolumn{1}{c}{ Explanation of Variables } & Symbol & \multicolumn{1}{c}{ Unit } \\
\hline Technical efficiency (estimated by authors) & te & Number \\
Percentage of revenue from exports to total revenue of firms & pretrf & $\%$ \\
Number of product innovations of firms & $n p i f$ & Number \\
Number of process innovations of firms & $n p r i f$ & Number \\
Firm's sales growth over last 3 years [Increased =1; Decreased =0] & fsg & Number \\
Firm have foreign collaboration [Yes=1; No=0] & fhfc & Number \\
Firm acquired foreign firm [Yes=1; No=0] & faff & Number \\
Biggest competitors of firm [Foreign firm=1; Local firm=0] & bcf & Number \\
Firm have growth/ scaling up plans in next 2-3 years [Yes=1; No=0] & fhgsp & Number \\
Firm have quality certification [Yes=1; No=0] & fhqc & Number \\
Firm acquired process/product patents [Yes=1; No=0] & fappp & Number \\
In-house R\&D expertise of firms [Yes=1; No=0] & ihrdef & Number \\
Linkages with public R\&D institutions -firms [Yes=1; No=0] & Iprdif & Number \\
Linkages with public technology support institutions of firms [Yes=1; No=0] & Iprdtsf & Number \\
Proficiency to improve processes of firms [Yes=1; No=0] & pipf & Number \\
Produce new or improved products of firms [Yes=1; No=0] & pnpf & Number \\
Acquire product/process patent of firms [Yes=1; No=0] & apppf & Number \\
Waste management capabilities of firms [Yes=1; No=0] & wmcf & Number \\
Firm face problems of shortage of skilled workforce [Yes=1; No=0] & ffpssw & Number \\
\hline Source: Bas
\end{tabular}

\footnotetext{
Source: Based on field survey.
}

SPSS statistical software is used for descriptive analysis of data and STATA statistical software is used to run proposed regression models. For the above-mentioned investigation, regression coefficients of explanatory variables are estimated using ordinary least square (OLS) estimation model.

\section{Empirical Results}

\subsection{Brief Discussion on Descriptive Results}

Brief explanation of estimated $T E$ of selected firms and other indicators are presented in Table 2. It provides the descriptive information on estimated TE and basic characteristic of firms. The values of standard deviation and variance are less than one for most of factors (except, percentage of revenue from exports to total revenue of firms, number of product innovations of firms, and number of process 
innovations of firms) thus it shows that collected data was normally distributed and do not have leverages.

Table 2: Description of dependent and independent variables.

\begin{tabular}{lrrrrr}
\hline \multicolumn{1}{c}{ Total Obs. } & \multicolumn{2}{c}{$\mathbf{1 5 4}$} & \multicolumn{2}{c}{ Total Industry } & $\mathbf{7}$ \\
\hline Variables & Minimum & Maximum & Mean & Std. Dev. & Variance \\
\hline Pretrf & 0.7992 & 0.9982 & 0.9857 & 0.0226 & 0.0005 \\
Npif & 0 & 100 & 17.2662 & 28.0518 & 786.9025 \\
Nprif & 0 & 30 & 1.5260 & 4.2229 & 17.8327 \\
Fsg & 0 & 100 & 1.7792 & 8.7636 & 76.8006 \\
Fhfc & 0 & 1 & 0.5130 & 0.5015 & 0.2515 \\
Faff & 0 & 1 & 0.1364 & 0.3443 & 0.1185 \\
Bcf & 0 & 1 & 0.0909 & 0.2884 & 0.0832 \\
Fhgsp & 0 & 1 & 0.1494 & 0.3576 & 0.1279 \\
Fhqc & 0 & 1 & 0.8182 & 0.3870 & 0.1497 \\
Fappp & 0 & 1 & 0.7273 & 0.4468 & 0.1996 \\
Ihrdef & 0 & 1 & 0.1623 & 0.3700 & 0.1369 \\
Lprdif & 0 & 1 & 0.8506 & 0.3576 & 0.1279 \\
Lprdtsf & 0 & 1 & 0.7320 & 0.4444 & 0.1975 \\
Pipf & 0 & 1 & 0.6104 & 0.4893 & 0.2394 \\
Pnpf & 0 & 1 & 0.9026 & 0.2975 & 0.0885 \\
Apppf & 0 & 1 & 0.9091 & 0.2884 & 0.0832 \\
Wmcf & 0 & 1 & 0.5325 & 0.5006 & 0.2506 \\
Ffpssw & 0 & 1 & 0.9416 & 0.2353 & 0.0554 \\
\hline
\end{tabular}

Source: Estimated by authors.

\subsection{Statistical Inference on Estimated Technical Efficiency (TE)}

The mean value of estimated technical efficiency (TE) of undertaken firms in 7 industries is given in Figure 3. The TE for 7 industries using four different empirical models. The value of TE in 7 manufacturing industries is estimated using a stochastic frontier production function approach (SFPFA). Estimated results specify that all industries (except textiles and apparels) have more than 94\% TE in production activities of firms in the Indian manufacturing sector. So, these industries have the ability to maintain production scale efficiently. However, there is a high probability to increase production activities of firms using technology up-gradation and advancement in India. Firms in the textiles and apparel industries have $86 \%$ technical efficiency. Thus, firms in textiles and apparels industry have relatively lower technical efficiency as compared to other industries. Hence, it is suggested to improve the TE of this sector using effective policy. 


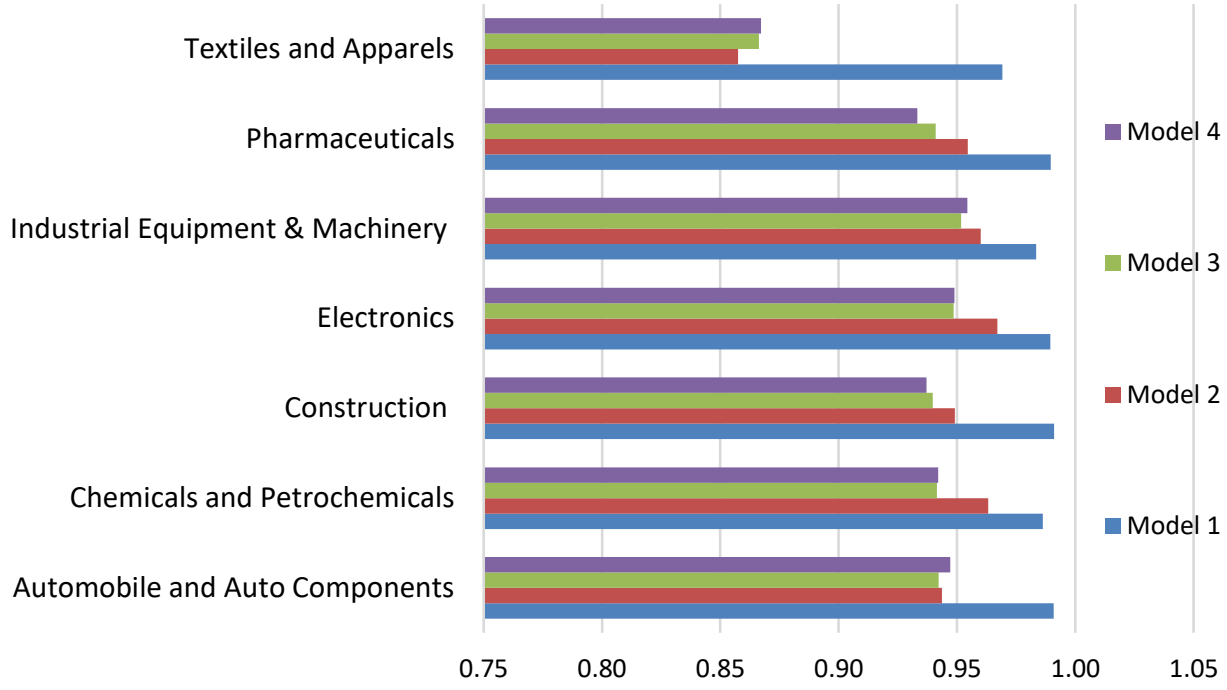

Figure 3. Mean value of estimated technical efficiency (TE) of 7 Industries

Source: Estimated by authors.

\subsection{Technical Efficiency (TE) Affecting Factors}

Regression results that assess the impact of IPRs and S\&T related indicators on estimated technical efficiency of firms is given in Table 3. The regression coefficients of most factors with the technical efficiency of firms is found positive and statistically significant. Thus, these factors would be helpful to improve the technical efficiency of undertaken firms. Results show that most factors like process innovation of firms, process patents, and product patents, in-house R\&D expertise of firms and linkages of firms with public technological support research institutions have a positive association with TE of firms. Estimates also indicate that IPRs and S\&T related factors play a vital role to increase the technical efficiency of firms. Here, it can be justified that process innovation, process patents and product patents are the crucial components of IPRs. Thus, here it can be argued that IPRs related factors would be useful to increase the TE of firms.

Aforementioned estimates are consistent with various studies which show the positive association of patenting with TE of firms, growth of manufacturing sector and economic development (e.g., Yueh, 2007; Janjua \& Samad, 2007; Sattar \& Mahmood, 2011; Sahu \& Narayanan, 2011; Pattnayak \& Chadha, 2013; Odilpova, 2016; Kumar \& Sharma, 2016; Singh, Acharya \& Chavda, 2017; Singh, Ashraf \& Acharya, 2017). Firm's sale growth, firm's scaling-up plan, proficiency of the firm to improve the process and ability of a firm to produce new or improved products are positively associated with the technical efficiency of firms. Furthermore, the waste management capabilities of firms, the percentage of revenue from exports to total revenue of firms and quality certification of firms are also essential to increase the 
technical efficiency of firms. Sahu and Narayanan (2015) have also found a significant impact of environmental certification on the technical efficiency of the Indian manufacturing sector. The skilled workforce is also positively correlated with the technical efficiency of firms. Thus, Indian manufacturing firms are necessary to give more importance to previously mentioned factors to improve the $T E$ of firms.

Table 3: Association of estimated technical efficiency of firms with explanatory variables

\begin{tabular}{|c|c|c|c|c|c|c|}
\hline Number of obs. & 154 & \multirow{2}{*}{\multicolumn{2}{|c|}{$\begin{array}{l}R \text {-squared } \\
\text { Adj. R-squared }\end{array}$}} & \multicolumn{3}{|l|}{0.2237} \\
\hline F-Value & 2.15 & & & 0.1195 & & \\
\hline Prob $>F$ & 0.0073 & \multicolumn{2}{|c|}{ Root MSE } & 0.0213 & & \\
\hline$T E=D V$ & Reg. Coef. & Std. Err. & $t$-Value & $P>|t|$ & \multicolumn{2}{|c|}{ [95\% Conf. Interval] } \\
\hline npif & -0.0009 & 0.0005 & -1.80 & 0.074 & -0.0018 & 0.0001 \\
\hline nprif & 0.0003 & 0.0002 & 1.30 & 0.195 & -0.0002 & 0.0007 \\
\hline$f s g$ & 0.0052 & 0.0038 & 1.36 & 0.175 & -0.0023 & 0.0127 \\
\hline fhfc & -0.0193 & 0.0067 & -2.89 & 0.004 & -0.0325 & -0.0061 \\
\hline faff & -0.0111 & 0.0074 & -1.49 & 0.139 & -0.0258 & 0.0036 \\
\hline$b c f$ & 0.0092 & 0.0055 & 1.68 & 0.094 & -0.0016 & 0.0201 \\
\hline fhgsp & 0.0036 & 0.0051 & 0.71 & 0.481 & -0.0064 & 0.0136 \\
\hline fappp & 0.0027 & 0.0051 & 0.53 & 0.596 & -0.0073 & 0.0127 \\
\hline ihrdef & 0.0053 & 0.0061 & 0.87 & 0.384 & -0.0067 & 0.0174 \\
\hline Iprdtsf & 0.0131 & 0.0047 & 2.79 & 0.006 & 0.0038 & 0.0224 \\
\hline pipf & 0.0025 & 0.0066 & 0.37 & 0.711 & -0.0106 & 0.0155 \\
\hline pnpf & 0.0033 & 0.0065 & 0.51 & 0.611 & -0.0096 & 0.0162 \\
\hline apppf & 0.0058 & 0.0044 & 1.31 & 0.191 & -0.0029 & 0.0146 \\
\hline$w m c f$ & 0.0015 & 0.0081 & 0.18 & 0.858 & -0.0145 & 0.0174 \\
\hline ffpssw & 0.0052 & 0.0039 & 1.32 & 0.189 & -0.0026 & 0.0129 \\
\hline pretrf & 0.0001 & 0.0001 & 0.45 & 0.655 & -0.0001 & 0.0002 \\
\hline fhqc & 0.0001 & 0.0040 & 0.01 & 0.993 & -0.0079 & 0.0080 \\
\hline Iprdif & -0.0158 & 0.0057 & -2.79 & 0.006 & -0.0270 & -0.0046 \\
\hline Con. Coef. & 0.9690 & 0.0102 & 95.36 & 0 & 0.9489 & 0.9891 \\
\hline
\end{tabular}

Source: Estimated by authors.

\section{Conclusion and Policy Recommendations}

The prime aim of this study was to examine the technical efficiency (TE) of randomly selected 154 firms using the stochastic frontier production function approach (SFPFA). These firms are considered from 7 different industries of Indian manufacturing sector i.e. given as: (i) Automobile and Auto Components, (ii) Construction (Equipment, Materials \& Technology), (iii) Chemicals and Petrochemicals, (iv) Industrial Equipment \& Machinery (Electrical Machinery), (v) Electronics, (vi) Pharmaceuticals, and (vii) Textiles and Apparels. For this, it includes firm-level data of the above-mentioned industries across Indian states. These firms are taken from Maharashtra, Gujarat, Tamil Nadu, Karnataka, Telangana, Delhi, Uttar Pradesh, Punjab and Haryana states of India. The regression coefficients of explanatory variables with annual turnover of firms are estimated using a log-linear 
regression model under ordinary least square estimation. Thereupon, it estimates the impact of IPRs and S\&T related indicators on estimated TE of firms using a linear regression model.

Mean values of estimated technical efficiency (TE) of various firms in 7 industries indicate that these (except textiles and apparels) have more than $94 \%$ technical efficiency in production activates in the Indian manufacturing sector. Thus, these industries are efficient to maintain production activities. Also, there is a high probability to increase production activities of firms using technology up-gradation and advancement in Indian manufacturing industries. Firms in the textiles and apparel industry have $86 \%$ technical efficiency, thus firms in this industry have relatively lower technical efficiency as compared to other industries. Hence, it is essential to adopt a conducive policy to increase the technical efficiency of firms in textiles and apparel industry in the Indian manufacturing sector.

Empirical results which assess the influence of IPRs and S\&T related factors, and other variables on $T E$ of firms indicate that $T E$ of firms is positively associated with percentage of revenue from exports to total revenue of firms, number of process innovations of firms, firm's sales growth, firm have growth/ scaling up plans, firm have quality certification, firm acquired process/product patents, in-house R\&D expertise of firms, linkages with public technology support institutions of firms, proficiency to improve processes of firms, produce new or improved products of firms, acquire product/process patents of firms, waste management capabilities of firms, and skilled workforce. Estimates clearly specify that the TE of firms would be improved as increases in previously mentioned variables. Previous studies like Dogan et al. (2016) have claimed that a firm's performance is significantly associated with firm owner and employees, social abilities, education level, capabilities, and skills (Dogan et al., 2016).

Empirical results of the study also provide several policy suggestions such as: Indian government needs to increase extensive public spending on R\&D to make India as a globally competitive economy in innovation (Bhat, 2014; Tyagi \& Nauryal, 2016; Singh \& Ashraf, 2019). It would be helpful to increase the consciousness of researchers and scientists to do more research for discovering more production technologies in emerging sectors such as biotechnology, pharmaceutical, agriculture, environmental and other sector of manufacturing units (Sahu \& Narayanan, 2011; Tyagi \& Nauryal, 2016; Mishra, 2019). Furthermore, R\&D activities would be effective to create innovation and it would work as an essential driver to maintain the long-term performance of technology-based-firms (Dogan et al., 2016; Singh \& Ashraf, 2019).

In India, imitations practice of technologies must be replaced with innovation in the manufacturing sector (Mishra, 2019). It would stimulate the domestic companies to increase their involvement in science $\&$ technology and innovation; subsequently it would be helpful for India to make an innovative champion in the world (Srivastava, 2015). National policymakers need to adopt a new strategy that leverages and 
recognizes and harnesses the innovative potential of the informal sector economy through technological advancement (Sheikh, 2014). It is apparent that Indian researchers and scientists have an insignificant knowledge of IPRs, technology transfer and technology commercialization. Hence, for India, it is essential to adopt effective IPRs and S\&T policies to utilize the existing technologies in manufacturing industries, which is discovered by Indian research institutions and universities. It would be helpful for Indian MSMEs to increase their intellectual powers in globally competitive economies. Indian MSMEs need to buy technologies from Indian research academia and universities to boost the growth of the manufacturing sector.

In addition, it is observed that India does have a low number of technology transfer offices (TTOs) in Indian research academia and universities. Thus, there is a barrier to create technological platforms in Indian research institutions. TTOs are helpful for a smooth transfer of technology and commercialization from research academia to existing industries (BayhDole25, 2006; Stephen, 2010; Ray \& Saha, 2010; Mysore, 2015; Chen, Patton \& Kenney, 2016; Singh \& Ashraf, 2019). Moreover, TTOs would be useful to create a market for existing industries to buy technologies and innovation discover by research organizations. Further, it would maintain the academia-industry interface which boosts the growth of Indian MSMEs (Merz \& Biniok, 2010; Singh \& Ashraf, 2019). Furthermore, TTOs may be useful to create more business enterprises in emerging economies like India (Wonglimpiyarat, 2012). There is essential to increase the contribution of private players to invest R\&D fund in research academia and research universities. R\&D funding for research organizations from private players would work as a significant driver to create a conducive and effective platform for technology transfer and commercialization across firms and industries in India (Srivastava \& Chandra, 2012; Ali \& Husain, 2014; Aruna, 2015; Dogan et al., 2016; Mishra, 2019; Singh \& Ashraf, 2019).

Also, Indian research academia has a low possibility to promote academic entrepreneurship and start-ups. Thus, the creation of academic start-ups and entrepreneurship would increase the attention of industries to make collaboration with research academia and universities. For this, more financial support for a hightech start-up must be given by the Government of India. It would be useful to increase the growth of Indian MSMEs. Also, it is realized that high-tech start-ups have a high possibility to nurture effectively (Krishna \& Subrahmanya 2015), thus it is suggested that Indian government needs to give more focus to create high-tech start-ups to maintain the growth of manufacturing sector. Moreover, it promotes linkages between large, medium and small enterprises in India (Abhyankar, 2014). For this, there is essential to promote high-tech start-ups and high-technology based enterprises in Indian research organizations. Subsequently, it would be beneficial to create more jobs for skilled and unskilled workforce. Most specifically, Indian manufacturing firms also need to adopt long-term strategies (such as minimizing operating expenditure, advertisement, and marketing expenditure) to improve the export of products (Tyagi \& Nauryal, 2016). Subsequently, it would provide them better return and profit as well. 


\section{Acknowledgments}

This research article is one of a crucial part of Post-Doctorate research of the first author. The prime author is grateful to the Entrepreneurship Development Institute of India (EDII), Ahmedabad for providing financial support and resources to writing this research paper. The authors are also grateful to Professor Sunil Shukla (Director), EDI of India to providing all research facilities to undertake this research. The research is also presented in the $9^{\text {th }}$ Conference on "Excellence in Research and Education" organized at IIM Indore, India [May 3-6, 2018]. The authors are also grateful to the conference's participants who could give conclusive comments and suggestions to increase the strength of this research article.

\section{References}

Abhyankar, R. (2014). The Government of India's role in promoting innovation, Technology Innovation Management Review, 4(8), 11-17. https://doi.org/10.22215/timreview818

Aigner, D., Lovell, C., \& Schmidt, P. (1977). Formulation and estimation of stochastic frontier production function models, Journal of Econometrics, 6(1), 21-37. https://doi.org/10.1016/0304-4076(77)90052-5

Akpan, S. B., Ukoha, O. O., Onyenweaku, C. E., \& Johan, D. E. (2012). Empirical relationship among technical efficiency, macroeconomic variables and industrial policy regimes: A case study of sugar industry in Nigeria, International Journal of Economics and Management Sciences, 1(10), 01-11.

Ali, A., \& Husain, F. (2014). MSME's India: Problems, solutions and prospectus in present scenario, International Journal of Engineering and Management Sciences, 5(2), 109-115.

Alvarez, R., \& Crespi, G. (2011). Determinants of technical efficiency in small firms, Small Business Economics, 20 (1), 233-244. https://doi.org/10.1023/A:1022804419183

Arcanjo, M. (2019). Climate change and the public health dilemma in India, A Climate Institute Publication, New York Avenue, Washington DC.

Aruna, N. (2015). Problems faced by micro, small and medium enterprises - A special reference to small entrepreneurs in Visakhapatnam, IOSR Journal of Business and Management, 17(4), 43-49.

Bawa, S. K., \& Chattha, S. (2016). Performance evaluation of the intermediary channels of life insurance industry in India, Eurasian Journal of Business and Economics, 9(17), 51-65. https://doi.org/10.17015/ejbe.2016.017.04

BayhDole25 (2006). The Bayh-Dole Act at 25. A Publication of BayhDole25, Inc., New York.

Bhat, T. P. (2014). India: Structural changes in the manufacturing sector and growth prospect, Working Paper No 173, Institute for Studies in industrial Development, New Delhi.

Bhatia, A., \& Mahendru, M. (2015). Assessment of technical efficiency of public sector bank in India using data envelopment analysis, Eurasian Journal of Business and Economics, 8(15), 115-140. https://doi.org/10.17015/ejbe.2015.015.06

Chatterjee, N., \& Das, N. (2016). A study on the impact of key entrepreneurial skills on business success of Indian micro-entrepreneurs: A case of Jharkhand region, Global Business Review, 17(1), 1-16. https://doi.org/10.1177/0972150915610729 
Chaudhuri, D. D. (2016). Impact of economic liberalization on technical efficiency of firms: Evidence from India's electronics industry, Theoretical Economics Letters, 6(1), 549-560. https://doi.org/10.4236/tel.2016.63061

Chavas, J. P., \& Aliber, M. (1993). An analysis of economic efficiency in agriculture: A nonparametric approach, Journal of Agricultural and Resource Economics, 18(1):1-16.

Chen, A., Patton, D., \& Kenney (2016). University technology transfer in China: A literature review and taxonomy, Brief Working Paper No 2016-5, Berkeley University of California. https://doi.org/10.1007/s10961-016-9487-2

Debnath, R. M., \& Sabastian, V. J. (2014). Efficiency in the Indian iron and steel industry - an application of data envelopment analysis, Journal of Advances in Management Research, 11(1), 4-19. https://doi.org/10.1108/JAMR-01-2013-0005

Dogan, B., Albeni, M., Baydar, V., \& Akcayir, O. (2016). A research on the performance and characteristics of the firms in Turkish manufacturing industry, Eurasian Journal of Business and Economics, 9(17):67-86. https://doi.org/10.17015/ejbe.2016.017.05

Fahmy-Abdullah, M., Ismail, R., Sulaiman, N., \& Talib, B. A. (2017). Technical efficiency in transport manufacturing firms: Evidence from Malaysia, Asian Academy of Management Journal, 22(1), 57-77. https://doi.org/10.21315/aamj2017.22.1.3

Falvey, R., \& Foster, N. (2006). The role of intellectual property rights in technology transfer and economic growth theory and evidence, United Nations Industrial Development Organization (UNIDO), Vienna.

Faruq, H. A., \& Yi, D. (2010). The determinants of technical efficiency of manufacturing firms in Ghana, Faculty Scholarship, Paper No. 62. https://doi.org/10.2202/1524-5861.1646

Gebresilassie, Y. H., \& Nyatanga P. (2017). Efficiency of the Ethiopian health extension program: An application of data envelopment analysis, Eurasian Journal of Business and Economics, 10(19), 99-126. https://doi.org/10.17015/ejbe.2017.019.06

Ghani, E., Kerr, W. R., \& O'Connell, S. (2013). Spatial determinants of entrepreneurship in India, Regional Studies, 48(6), 1071-1089. https://doi.org/10.1080/00343404.2013.839869

Green, R. A. (2014). Can "Make in India" make jobs? The challenges of manufacturing growth and high-quality job creation in India. James A. Baker III Institute for Public Policy, Rice University, Houston. http://www.bakerinstitute.org/media/files/files/9b2bfOa2/Econ-pubMakelnIndia-121514.pdf

Hamjah, M. A. (2014). Climatic effects on cotton and tea production in Bangladesh and measuring efficiency using multiple regression and stochastic frontier model respectively, Mathematical Theory and Modeling, 4(3), 86-98.

Hoda, A., \& Rai, D. K. (2014). Trade and investment barriers affecting international production network in India, Working Paper No 281, National Council for Research on International Economic Relations, New Delhi.

Ikram, A., Su, Q., \& Sadiq, M. A. (2016). Technical efficiency and its determinants: An empirical study of surgical instruments cluster of Pakistan, The Journal of Applied Business Research, 32(2), 647-660. https://doi.org/10.19030/jabr.v32i2.9601

Janjua, P. Z., \& Samad, G. (2007). Intellectual property rights and economic growth: The case of middle income developing countries, The Pakistan Development Review, 46(4), 711-722. https://doi.org/10.30541/v46i4Ilpp.711-722

Kapoor, R. (2016). Technology, jobs and inequality: Evidence from India's manufacturing 
sector, Working Paper No 313, Indian Council for Research on International Economic Relations, New Delhi.

Kea, S., Li, H., \& Pich, L. (2016). An analysis of technical efficiency for household's rice production in Cambodia: A case study of three districts in Battambang province, Preprints, 1(1), 1-21. https://doi.org/10.20944/preprints201611.0046.v1

Krishna, H. S., \& Subrahmanya, M. H. B. (2015). Transnational entrepreneurship and Indian high-tech start-up survival: An empirical investigation, South Asian Journal of Management, 22(2), 82-98.

Kumar, A., \& Ayedee, A. (2018). Social media tools for business growth of SMES, Journal of Management, 5(3), 137-142.

Kumar, A., Sharma, P., \& Ambrammal, S. K. (2014). Climatic effects on food grain productivity in India: A crop wise analysis, Journal of Studies in Dynamics and Change, 1(1), 38-48.

Kumar, A., Sharma, P., \& Ambrammal, S. K. (2015). Climatic effects on sugarcane productivity in India: A stochastic production function application, International Journal of Economics and Business Research, 10(2), 179-203. https://doi.org/10.1504/IJEBR.2015.070984

Kumar, A., Sharma, P., \& Joshi, S. (2016). Assessing the impacts of climate change on land productivity in Indian crop agriculture: An evidence from panel data analysis, Journal Agricultural Science and Technology, 18(1), 1-13.

Kumar, S., \& Arora, N. (2012). Evaluation of technical efficiency in Indian sugar industry: An application of full cumulative data envelopment analysis, Eurasian Journal of Business and Economics, 5(9), 57-78.

Kumar, S., \& Sharma, R. (2016). Patenting and technical efficiency of manufacturing firm in India: Evidence from medium and high technology firms, In: Siddharthan N., Narayanan K. (eds.), Technology, India Studies in Business and Economics, Springer, Singapore. https://doi.org/10.1007/978-981-10-1684-4_3

Kumarasamy, T., \& Srinivasan, J. (2017). Impact of social media applications on small and medium business entrepreneurs in India, International Journal of Commerce and Management Research, 3(10), 50-53.

Kumbhakar, S., \& Lovell, C. A. K. (2003). Stochastic frontier analysis, Cambridge: Cambridge University Press.

Lakshmi, V., Mahboob, A., \& Choudhry, A. (2017). A study on impact of social media on small and medium enterprises, International Journal of Scientific Development and Research, 2(11), 64-71.

Lehtimaki, J., \& Lehtimaki, J. (2016). Impact of knowledge capital on performance of firms: A case of firms in Finland, Eurasian Journal of Business and Economics, 9(18), 41-59. https://doi.org/10.17015/ejbe.2016.018.03

Mahajan, V., Nauriyal D. K., \& Singh, S. P. (2014). Efficiency and ranking of Indian pharmaceutical industry: Does type of ownership matter?, Eurasian Journal of Business and Economics, 7(14), 29-50. https://doi.org/10.17015/ejbe.2014.014.02

Meeusen, W., \& Van den Broeck, J. (1977). Efficiency estimation from Cobb-Douglas production functions with composed error, International Economic Review, 18(2), 435-444. https://doi.org/10.2307/2525757

Merz, M., \& Biniok, P. (2010). How technological platforms reconfigure science-industry relations: The case of micro-and nanotechnology, Minerva, 48(2), 105-124. 
https://doi.org/10.1007/s11024-010-9146-y

Mishra, P. (2019). How have mergers and acquisitions affected financial performance of firms in Indian manufacturing sector? Eurasian Journal of Business and Economics, 12(23), 79-96. https://doi.org/10.17015/ejbe.2019.023.05

Munisamy, S., Fon, C. F., \& Khin, E. W. S. (2015). Innovation and technical efficiency in Malaysian family manufacturing industries, Journal of Economics \& Finance Studies, 3(4), 50 67. https://doi.org/10.18533/jefs.v3i03.109

Mysore, S. (2015). Technology commercialization through licensing: Experiences and lessonsA case study from Indian horticulture sector, Journal of Intellectual Property Rights, 20(1), 363374.

Narwal, K. P., \& Pathneja, S. (2015). Determinants of productivity and profitability of Indian banking sector: A comparative study, Eurasian Journal of Business and Economics, 8(16), 3558. https://doi.org/10.17015/ejbe.2015.016.03

Ng'ombe, J., \& Kalinda, T. (2015). A stochastic frontier analysis of technical efficiency of maize production under minimum tillage in Zambia, Sustainable Agricultural Research, 4(2), 31-45. https://doi.org/10.5539/sar.v4n2p31

Odilpova, S. (2016). Patent protection, intelligence and economic growth: A cross-country empirical investigation, Paper No 70842, MPRA.

Okoye, B. C., Abass, A., Bachwenkizi, B., Asumugha, G., Alenkhe, B., Ranaivoson, R., Randrianarivelo, R., Rabemanantsoa, N., \& Ralimanana, I. (2016). Differentials in technical efficiency among smallholder cassava farmers in Central Madagascar: A Cobb Douglas stochastic frontier production approach, Cogent Economics \& Finance, 4(1), 1-10. https://doi.org/10.1080/23322039.2016.1143345

Patnaik, K. S. K., \& Satyaprakash, B. (2015). Role of social media in the growth of small scale industries in Coastal Orissa, IOSR Journal of Business and Management, 17(11), 01-03.

Pattnayak, S. S., \& Chadha, A. (2013). Technical efficiency of Indian pharmaceutical firms: A stochastic frontier function approach. http://conference.iza.org/conference_files/pada2009/pattnayak_s5193.pdf.

Rajesh, R. S. N. (2007). Technical efficiency in the informal manufacturing enterprises: Firm level evidence from an Indian state, Paper No 7816, MPRA. http://mpra.ub.unimuenchen.de/7816/

Ray, A. S., \& Saha, S. (2010). Patenting public- funded research for technology transfer: A conceptual -Empirical synthesis of U.S. evidence and lesson for India, Working Paper 244, Indian Council for Research on International Relations, New Delhi. https://doi.org/10.1111/j.1747-1796.2010.00410.x

Sahu, P. K. (2015). Technical efficiency of domestic and foreign firms in Indian manufacturing: A firm level panel analysis, Indian Journal of Economic \& Research, 4(2), 7-21. https://doi.org/10.17010/aijer/2015/v4i2/65534

Sahu, S. K., \& Narayanan, K. (2011). Determinants of energy intensity in Indian manufacturing industries: A firm level analysis, Eurasian Journal of Business and Economics, 4(8), 13-30.

Sahu, S. K., \& Narayanan, K. (2015). Environmental certification and technical efficiency: A study of manufacturing firms in India, $J$ Ind Compet trade, DOI 10.1007/s10842-015-0213-9. https://doi.org/10.1007/s10842-015-0213-9

Sattar, A., \& Mahmood, T. (2011). Intellectual property rights and economic growth: Evidence 
from high, middle and low income countries, Pakistan Economic and Social Review, 49(2), 163186.

Sen, J., \& Das, D. (2016). Technical efficiency in India's unorganized manufacturing sector: A non-parametric analysis, International Journal of Business and Management, 4(4), 92-101. https://doi.org/10.20472/BM.2016.4.4.005

Sheikh, F. A. (2014). Science, technology and innovation policy 2013 of India and informal sector innovations, Current Science, 106(1), 21-23.

Shugurov, M. V. (2015). TRIPS agreement, international technology transfer and least developed countries, Journal of Advocacy, Research and Education, 2(1), 74-85.

Singh, A. K., \& Ashraf, S. N. (2019). Viability of Bayh-Dole Act of USA in context of India: Critical evidence from review of literature, JNNCE Journal of Engineering \& Management, 3(1), 7-22.

Singh, A. K., \& Issac, J. (2018). Impact of climatic and non-climatic factors on sustainable livelihood security in Gujarat state of India: A statistical exploration, Agriculture and Food Sciences Research, 5(1), 30-46. https://doi.org/10.20448/journal.512.2018.51.30.46

Singh, A. K., Acharya, S. R., \& Chavda, P. (2017). Implications of intellectual property rights and socio-economic factors on growth of manufacturing sector in selected cross economies: An empirical assessment, in Sasi Misra, Sunil Shukla and Ganapathi Batthini (Eds.), Proceedings of the 12th Biennial Conference on Entrepreneurship Organized by EDII Ahmedabad (pp. 262279), Bookwell Publishing House, New Delhi.

Singh, A. K., Ahmad, M. M., \& Sharma, P. (2017). Implications of socioeconomic factors on food security in selected economies: An empirical assessment, Journal of Global Economics, Management Business Research, 8(2), 103-115.

Singh, A. K., Ashraf, S. N., \& Acharya, S. R. (2017). Viability of Bayh Dole Act of USA in the context of India: Critical evidence from review of literature, in Sasi Misra, Sunil Shukla and Ganapathi Batthini (Eds.), Proceedings of the 12th Biennial Conference on Entrepreneurship Organized by EDII Ahmedabad (pp. 235-252). Bookwell Publishing House, New Delhi.

Singh, A. K., Narayanan, K. G. S., \& Sharma, P. (2018). Influence of climate variability on sugarcane farming in India: An empirical research, in Nandan Nawn and Joy Elamon (Eds.), Proceedings of the 9th Biennial Conference 2017 of the Indian Society for Ecological Economics (INSEE) on "Sustainability, Institutions, Incentives: Voices, Policies and Commitments", Organized by Kerala Institute of Local Administration, Thrissur, Indian Society for Ecological Economics, New Delhi.

Singh, A. K., Narayanan, K. G. S., \& Sharma, P. (2019). Measurement of technical efficiency of climatic and non-climatic factors in sugarcane farming in Indian states: Use of stochastic frontier production function approach, Climate Change, 5(19), 150-166.

Singh, A.K., \& Jyoti, B. (2019). Assessing the impact of climatic and socio-economic factors on food security in India and Thailand: An empirical analysis, SOCIALSCI Journal, 4(1), 115-134.

Singh, A.K., \& Sharma, P. (2018a). Implications of climatic and non-climatic variables on food security in developing economies: A conceptual review, MOJ Food Processing \& Technology, 6(1), 1-12. https://doi.org/10.15406/mojfpt.2018.06.00138

Singh, A.K., \& Sharma, P. (2018b). Measuring the productivity of food-grain crops in different climate change scenarios in India: An evidence from time series investigation, Climate Change, 4(16), 611-673.

Srinivasan, S., Bajaj, R., \& Bhanot, S. (2016). Impact of social media marketing strategies used by micro small and medium enterprise (MSMEs) on customer acquisition and retention, IOSR 
Ajay Kumar SINGH, Shah Nawaz ASHRAF \& Ashish ARYA

Journal of Business and Management, 18(1), 91-101.

Srivastava, P., \& Chandra, S. (2012). Technology commercialization: Indian university perspective, Journal of Technology Management \& Innovation, 7(4), 121-131. https://doi.org/10.4067/S0718-27242012000400010

Srivastava, V. (2015). Will Make in India initiative boost innovation?, Indian Management, 2(2), 42-45.

Stephen, T. K. (2010). Asian Initiatives on Bayh-Dole, with special reference to India: How do we make it more "Asian?", Chicago-Kent Journal of Intellectual Property, 10(10), 44-64.

Tyagi, S., \& Nauryal D. K. (2016). Profitability determinants in Indian drugs and pharmaceutical industry: An analysis of pre and post TRIPS period. Eurasian Journal of Business and Economics, 9(17), 1-21. https://doi.org/10.17015/ejbe.2016.017.01

$\mathrm{Vu}, \mathrm{H}$. D. (2016). Technical efficiency of FDI firms in the Vietnamese manufacturing sector, Review of Economic Perspectives, 16(3), 1-13. https://doi.org/10.1515/revecp-2016-0013

Wei, Y., \& Balasubramanyam, V. N. (2015). A comparative analysis of China and India's manufacturing sectors, Economic Working Paper No 003, Lancaster University Management School, UK. https://www.lancaster.ac.uk/media/lancaster-university/contentassets/documents/lums/economics/working-papers/LancasterWP2015_003.pdf

Wonglimpiyarat, J. (2012). Technology transfer and commercialization: Venture capital financing system of Thailand, The Journal of Private Equity, 16(1), 42-55. https://doi.org/10.3905/jpe.2012.16.1.042

Yueh, L. Y. (2007). Global intellectual property rights and economic growth, Northwestern Journal of Technology and Intellectual Property, 5(3), 434-448.

Zhou, Y. (2014). FDI and technical efficiency in manufacturing firms: A stochastic frontier approach, Master's Thesis, Paper 95. http://repository.usfca.edu/cgi/viewcontent.cgi?article=1102\&context=thes. 